\title{
Sand Gradation in Seasonal Rivers and their Suitability for Construction of Sand Dams in Kitui South, Kenya
}

Kennedy Mutati ${ }^{1 *}$, Johnson U Kitheka ${ }^{2}$ and Ezbon Otieno ${ }^{2}$

${ }^{1}$ Department of Agriculture, Water and Irrigation, County Government of Kitui, Kitui, Kenya

${ }^{2}$ Department of Hydrology and Water Resources Management, School of Water Resources and Technology, South Eastern Kenya University, Kitui, Kenya

"Corresponding author: Kennedy Mutati, Department of Agriculture, Water and Irrigation, County Government of Kitui, Kitui, Kenya, Tel: +254-723-585781; E-mail: kmutati@gmail.com

Received date: March 02, 2018; Accepted date: March 15, 2018; Published date: March 26, 2018

Copyright: (c) 2018 Mutati K, et al. This is an open-access article distributed under the terms of the Creative Commons Attribution License, which permits unrestricted use, distribution, and reproduction in any medium, provided the original author and source are credited.

\begin{abstract}
This study was undertaken in Kitui South in Kitui County in the south eastern parts of Kenya. The main objective of the study was to develop a spatial model that can be used for selection of suitable sites for sand dam in Kitui South. The study also assessed the spatial variation of sand grain sizes and how these determine the suitability of sites for the sand dams. Data analysis was done using three approaches. The first approach involved the use of the Remote Sensing (RS) technique where data was preprocessed and analyzed using Erdas Imagine software and Geographical Information Systems (GIS) for spatial modelling. The distribution of sand particle-sizes was based on sieve analysis on the sand samples collected from seasonal rivers in the study area. The seasonal rivers that were investigated in this study included Mwila, Kakya, Wiitu, Nguni, Ngunyumu, Muvuko, Kanzilu, Masaa, Katiliku, Ngulungu, Nzeeu, Koma and Katitika. Statistical analysis was done to establish the relationships between the various spatial components affecting sand particle distribution. The results from the spatial model which integrated all factors shows that $16 \%$ of the studied sites along the seasonal rivers in Kitui South were fairly suitable for construction of sand dams while $79 \%$ were classified as suitable and $5 \%$ are categorized as very suitable. Several sites in the central and the entire eastern parts of Mutha Ward were found not suitable for sand dam construction due to poor conditions such as the lack of suitable sand particles, lack of bedrock exposure on the riverbeds, flat terrain, very shallow stream banks, and weak soils on the riverbanks. Suitable sites for sand dams were found on the western and central areas of Kitui South where production and high accumulation of coarse sands was observed along the seasonal rivers. The areas near Mutomo hills and the rocky areas in Ikanga wards were found to be characterized by few excellent sites for sand dams. The optimum accumulation of different grades of sand in the seasonal rivers was found on streams with slope of between 1.5 and $6 \%$ that were dominated with 0 to $40 \%$ coarse sands, 0 to $30 \%$ fine gravels, 0 to $20 \%$ fine sands, and 20 to $80 \%$ medium sands. The accumulation of fine gravels was found to be closely related to the distribution of $D_{30}, D_{60}$ and $D_{90}$ sand particle-sizes $(0.4-4 \mathrm{~mm})$ while accumulation of coarse sands showed good relationship with the distribution of the medium size sand $(0.2-0.4 \mathrm{~mm})$. The accumulation of medium sands was equally high when the occurrence of coarse sands was minimal. Different grades of sand were found to be strongly influenced by the changes in the elevation of the stream especially with regard to the accumulation of the medium sands $(r=0.76)$ and coarse sands $(r=0.75)$. Out of 80 investigated sites, $59 \%$ of them were dominated with uniform sands $(\mathrm{Cu}<3), 30 \%$ were intermediate sands and only $11 \%$ were wellgraded sands $(\mathrm{Cu}>5)$. The study also found that $86 \%$ of the sites along the seasonal streams were dominated with medium sands while $10 \%$ were dominated with fine sands and the rest $(4 \%)$ dominated by coarse and gravelly sands. From the results this study concludes that $59 \%$ of the 80 sites that were investigated in this study have a high potential for providing suitable sites for sand dams in Kitui South.
\end{abstract}

Keywords: Sand dams; Particle size distribution; Hydrology; Water management; Kitui south; Kenya

\section{Introduction}

In Kenya $80 \%$ of the land is classified as arid and semi-arid and therefore suffer from water shortage [1]. The annual rainfall (500 to $1050 \mathrm{~mm} / \mathrm{yr}$ ) is considerable but is limited to two rainy seasons. Most of the ASALs in Kenya experience rainfall in short high intensity events that hardly infiltrate into the ground. Between these rainy seasons, communities in the rural areas in ASALs encounter drought with severe water shortages. In Kitui County for example rain disappears as runoff into ephemeral rivers that stand dry for the rest of the year. Given the expected increase in climate variability $[2,3]$ and the massive potential of rainwater harvesting in Africa [4], studying techniques of small scale water storage such as sand dams becomes increasingly important. In the recent past, there has been a growing recognition of the importance of sand dams as a low cost and robust means to enhance water availability in ASALs. Determining a suitable location for a sand dam involves evaluating the favorability of both the physical and environmental conditions [5]. The physical conditions include a number of factors. One is the availability of coarse sand supplied by the runoff along the river [6]. Coarse sand is preferred in this case because it allows water infiltration into the sand which is then stored for a given period and can be abstracted for both livestock and domestic uses [7]. Medium sands are also applicable when there is minimal supply of coarse sands [8]. Fine sands are not recommended due to their limited storage capacity. The availability of accessible bedrock below the accumulated sand along the riverbed is also important [9]. The bedrock acts as the foundation and anchoring point for the sand dam. The bedrock also ensures that the water that 
infiltrate into the sand matrix does not leak away from the subsurface storage [10].

The distribution of different sand particles along the streams varies from one point to the other. This is attributed to factors such the source geology, distance from the origin, and size of the sediments [11]. Respective sand gradation denoted as $\mathrm{D}_{10}, \mathrm{D}_{30}, \mathrm{D}_{50}$ and $\mathrm{D}_{90}$ are commonly used to show the distribution of sand particle sizes. This represents the first decile, third decile, fifth decile and the ninth decile respectively. The median size is represented as $D_{50}$ which means that half portion of the sand that accumulate at any given point along the river is larger than the particle size at that $\mathrm{D}_{50}$ and half of the sand is dominated with particles less than the value indicated at $\mathrm{D}_{50}$ [12]. A normal distribution curve would be attained when the dominant particle size is at $\mathrm{D}_{50}$ (median size). The median size varies from one point to the other along the seasonal rivers but if the size is between 0.4 to $2 \mathrm{~mm}$ (coarse sand), then the site would be taken as suitable for a sand dam.

The distribution of sand particle size is important but in order to maximize the storage capacity of the sand dams, assessment of uniformity and gradation of sand is also important. Uniformity of sand is defined by the Coefficient of Uniformity $(\mathrm{Cu})$ and sand gradation is defined by the Coefficient of gradation (Ck). These coefficients are influenced by changes in the particle size distribution mainly $\mathrm{D}_{10}, \mathrm{D}_{30}$ and $\mathrm{D}_{60}$. If the ratio between the particle size $\mathrm{D}_{60}$ and $\mathrm{D}_{10}$ is less than 3 then the sand will be considered uniform and well-graded when the ratio is greater than 5 [13]. Uniform sand are preferred due to high surface area for water storage in the sand dams. Practically, rivers exhibit characteristics changes as it extends down its course. These changes show a recognizable pattern and variation in terms of the energy, discharge, velocity, channel characteristics and load on the riverbed [14]. Since the rivers are in continuous interaction with the physical environment as well as climate and human factors considerable changes in varied temporal and spatial scales are observed in both the landforms and processes of rivers [15]. The river channel becomes wider and deeper and as a result its cross-sectional area increases. In the lower course bed load can only really be found in the form of fine sediments and muds, known as alluvium [16].

The analysis of sediments involves determination of the particlesizes, porosity and depth of the accumulated sediments. The sediments with high content of coarse sands and medium sands are deemed suitable for high storage capacity sand dams [17]. The river channels with clay sediments are not suitable due to low permeability [17]. The ideal sites should consist of consolidated rocks forming the base of the sand dam as well as the riverbanks. The river banks that consist of loose soil materials may not be suitable due to increased possibility of erosion of the banks and subsequent collapse of the sides of sand dams rendering the whole structure unstable.

\section{Study Area}

The study was carried out in Kitui South which is located in the southern parts of the Kitui County (Figure 1). The Kitui South extends roughly $200 \mathrm{~km}$ from north to south and $120 \mathrm{~km}$ from east to west with a surface area of $30,496 \mathrm{~km}^{2}$. The Southern part of Kitui South which is approximately $20 \%$ of the Kitui County land cover is occupied by the Tsavo East National Park. Kitui South is divided into six administrative wards namely, Mutomo, Mutha, Ikanga, Athi, Kanziko and Ikutha.

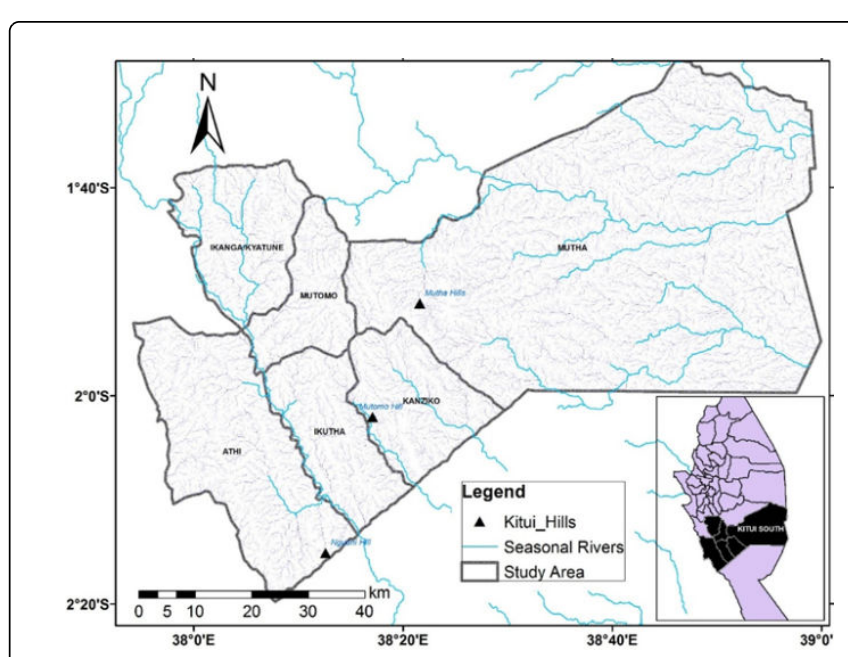

Figure 1: Location Kitui South in Kitui County in Eastern Kenya (Source: Author, 2017).

The area experiences two rainy seasons with two peaks in April-May (long rains) and November-December (short rains). The rest of the year is hot and dry. Air temperature ranges between $16^{\circ} \mathrm{C}$ and $34^{\circ} \mathrm{C}$ with mean maxima of $28^{\circ} \mathrm{C}$ and minima of $22^{\circ} \mathrm{C}$ (Borst and De Haas). The study area is well covered with seasonal rivers where the river discharge is characterized by high flows in April-May and NovemberDecember and extremely low or no discharge in the dry periods between January-March and July-October.

\section{Methodology}

\section{Sample collection}

Assessment of the stream morphology was done through measurement of the riverbank height, riverbed gradient and computation of the capacity of the reservoir to be constructed at the site. Sampling along streams was done at an interval of 500 meters to maximize comparison of sediments variation along a single river channel. Stream investigation was done from the 80 sampling sites indicated in Figure 2. The numbers indicated in Figure 2 represent the pattern used to collect $1 \mathrm{~kg}$ of a sample from the riverbed at a potential sand dam site. The representative samples were collected on the upstream side of the sand dam wall within the riverbed. A total of 80 samples of sand material were collected for analysis in this study form eighty (80) sampling points as indicated in Figure 2. 


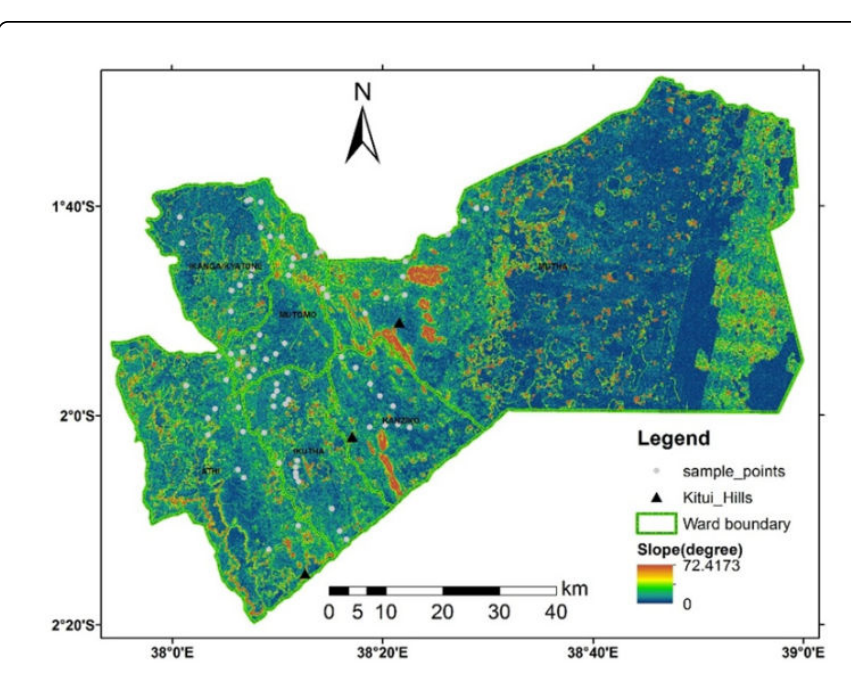

Figure 2: The general terrain of Kitui South area including the sampling sites where the sand samples were collected (Source: Author, 2017).

\section{Particle size analysis}

Dry sieving method was done to separate different grades of sand from eighty (80) samples collected from the field based on American Standard Test Method (ASTM) [18]. The samples were dried in an oven up to a temperature of $105^{\circ} \mathrm{C}$ for $3 \mathrm{hrs}$. At this point, each sample was spread on a tray at a thickness of about $1 \mathrm{~cm}$ to maximize surface areas for drying. It took eight (8) hours during the day time to dry each sample and then cooling overnight as recommended in ISO [19].

The standard sieves considered for sieve analysis based on ASTM on coarse soils were \#2 (4.75 mm), \#10 (2 mm), \#20 (0.85 mm), \#40 (0.43 $\mathrm{mm})$, \#60 (0.25 mm), \#100 (0.15 mm), and \#200 (0.075 mm). The loss observed during dry sieving was expressed as an error defined as the difference between the original sample weight and the sum of the individual retained fractions which was computed using the formula $[(\mathrm{Om}-\Sigma \mathrm{MR}) / \mathrm{Om}]^{\star} 100 \%$. The average error was $0.4 \%$ which was within the acceptable evaluation error that must not exceed $1 \%$ of the original sample weight [20].

Cumulative grading curves were drawn to determine sand particlesizes distribution at any given sand dam site. The third, fifth, sixth and the ninth deciles were denoted as $\mathrm{D}_{30}, \mathrm{D}_{50}, \mathrm{D}_{60}$, and $\mathrm{D}_{90}$, respectively. These parameters were used in the determination of soil Uniformity Coefficient $(\mathrm{Cu})$ and Coefficient of gradation (Ck) [12]. $\mathrm{Cu}$ and $\mathrm{Ck}$ were computed using the formulas $\left[\mathrm{Cu}=\mathrm{D}_{60} / \mathrm{D}_{10}\right]$ and $\left[\mathrm{Ck}=\mathrm{D}_{302} /\right.$ $\left(\mathrm{D}_{60}{ }^{*} \mathrm{D}_{10}\right)$ ] respectively. For the single-sized (uniform) soils, $\mathrm{Cu}$ and Ckis equal to 1 . If $\mathrm{Cu}$ is greater than 5 then it implies that the soil is well-graded. When Cuis less than 3, it means that the soil is uniform in size. Ck ranging between 0.5 and 2.0 indicates a well-graded soil but if less than 0.1 then the soils is possibly gap-graded [11]. The distribution of the different particle-sizes at any given sampling site was defined by the particle-sizes represented by $\mathrm{D}_{10}, \mathrm{D}_{30}, \mathrm{D}_{50}$, and $\mathrm{D}_{90}$ derived from the grading curves [20].

The study also used the median values $\left(D_{50}\right.$ in $\left.\mathrm{mm}\right)$ which represented the corresponding sand particle-size in millimeters that divided the cumulative curve into two where one half is above and the other half is below this particle sizes. The particle diameter at $D_{50}$ as well as at $\mathrm{D}_{10}, \mathrm{D}_{30}, \mathrm{D}_{60}$, and $\mathrm{D}_{90}$ were very important values in the analysis as they show how particle-sizes are distributed in a sand dam site and the uniformity of sand can also be determined [19]. These values provided more meaningful and representative statistics in terms of particle-size distributions unlike when using simple 'mode' and 'mean' to show the same. The significance of using the median sand grain size $\left(\mathrm{D}_{50}\right.$ in $\left.\mathrm{mm}\right)$ was also upheld in other related studies $[12,21]$.

\section{Results}

\section{Variations of sand gradation along the riverbeds}

Several seasonal rivers were found to be suitable sites for sand dam with uniform grade and appropriate particle sizes accumulated on the riverbeds (Figure 3) namely river Nzeeu, Katiliku, Memboo, Kanzilu, Kavuti, Muvuko, Tiva, Mwila, Mitanda, Nguuni, Ndiliu and Ngunyumu. River Nzeeu in Ikanga Ward at an elevation of $848 \mathrm{~m}$ had $23 \%$ fine gravel, $42 \%$ coarse sand, $30 \%$ medium sand and $4 \%$ of fine sand. At a lower elevation of $841 \mathrm{~m}$, Memboo River in Mutomo Ward had $0.7 \%$ of fine gravel, $8.1 \%$ coarse sand, $80.3 \%$ of medium sand and $10.5 \%$ of fine sand which shows a great impact of the change in elevation along the seasonal river. River Kanzilu in Mutha Ward showed high accumulation of fine gravel (28\%) at an elevation of 580 m near Makutano Kivili, $41 \%$ of coarse sand, and $28 \%$ of medium sand. Along the same river were other suitable sites for example Kwa Kikuyu at an elevation of $498 \mathrm{~m}$ with $2.6 \%$ fine gravel, $8.6 \%$ coarse sand, and $75 \%$ medium sand. At Kwa Musyimi site along Kanzilu river had $14 \%$ fine gravel, $42 \%$ coarse sand, and $41 \%$ medium sands. At an elevation of $468 \mathrm{~m}$, another site at Kwa Katu Kilonzo had least fine gravel of $0.7 \%, 8.9 \%$ of coarse sand but showed high accumulation of medium sand (85\%) hence suitable for a sand dam.

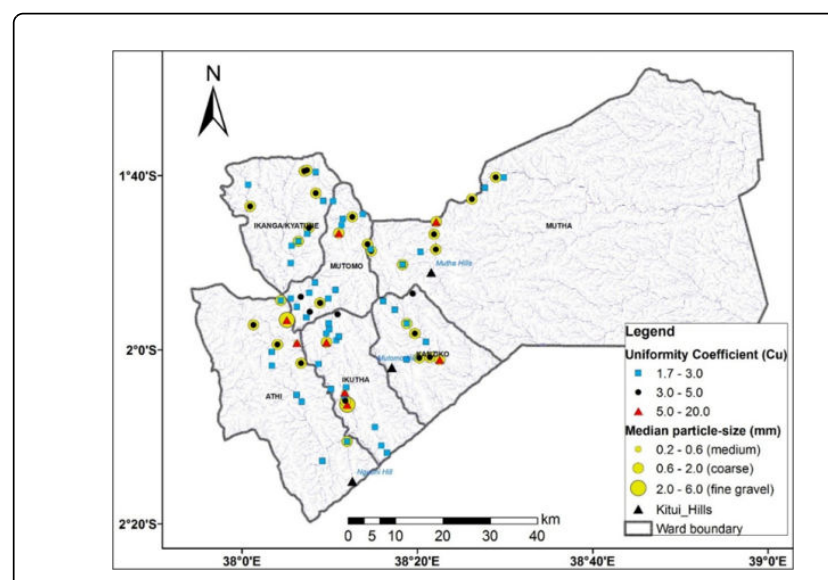

Figure 3: Relationship between the sand uniformity $(\mathrm{Cu})$ and the spatial distribution of median particle-size of sand in Kitui South at the potential sand dam sites (Source Author, 2017).

The particle-size distribution along the seasonal rivers in Kitui South ranged from $8 \%$ fine sands $(0.08 \mathrm{~mm}-0.15 \mathrm{~mm}), 66 \%$ medium sands $(0.25 \mathrm{~mm}-0.43 \mathrm{~mm}), 21 \%$ coarse sands $(0.85 \mathrm{~mm})$, and $5 \%$ fine gravel $(2 \mathrm{~mm}-4.75 \mathrm{~mm}) .13 .8 \%$ of the sands available along the seasonal rivers in Kitui South were found to be 'uniform graded medium sands', $3.8 \%$ were 'gap graded fine sands', $1.3 \%$ were 'uniform graded fine sand', $10 \%$ were 'uniform graded medium sand', $26.3 \%$ were found to be 'well-graded coarse sands', $6.3 \%$ were 'well-graded fine sand', and $48.8 \%$ were 'well graded medium sands. The results show 
that most of the investigated sites were dominated with medium sands and coarse sands in that order.

Uniform coarse sands are deemed the best for sand dam [10]. The parameters $\mathrm{Cu}$ and $\mathrm{Ck}$ were used to assess uniformity and gradation of the sands along the seasonal rivers in Kitui South. $\mathrm{Cu}<3$ indicates uniform soils while $\mathrm{Cu}>5$ indicates well-graded soils. Out of the 80 samples that were analyzed, 47 (59\%) of them were categorized as uniform sands $(\mathrm{Cu}<3), 24(30 \%)$ were intermediate and only $9(11 \%)$ were well graded $(\mathrm{Cu}>5)$. Out of the 47 sites observed with uniform sands, $86 \%$ were dominated with the medium sands and the rest $14 \%$ were coarse sands. The Coefficient of Uniformity $(\mathrm{Cu})$ varied between a maximum of 16.67 and a minimum of 1.74 resulting to a range of 14.93 and a mean of 3.42 (Figure 3). The results also showed that the coefficient of gradation, Ck varied between 2.55 and 0.33 , a range of 2.22 and a mean of 0.94 . These results imply that 47 (59\%) of the 80 sites are highly potential and suitable for sand dams.

\section{Sand accumulation and the dominant particle-sizes}

The distribution of different grades of sand namely; $\mathrm{D}_{10}, \mathrm{D}_{30}, \mathrm{D}_{50}$, and $\mathrm{D}_{90}$ were used to explain the relationship between the accumulation of fine gravels and the distribution of different grades of sands Figures $4 \mathrm{a}-4 \mathrm{~d})$. The particles represented as $\mathrm{D}_{10}$ show a moderate relationship with a coefficient of determination, $\mathrm{R}^{2}$ of 0.27 and a correlation coefficient of 0.52 . The distribution of particle size represented as $D_{10}$ ranges between 0.1 and $0.4 \mathrm{~mm}$ (fine to medium sands). In Figure $4 \mathrm{~b}$, the distribution of the particle-sizes represented as $\mathrm{D}_{30}$ ranges between 0.2 to $0.6 \mathrm{~mm}$ which simply indicate the occurrence of medium size sands. The relationship between the occurrence of medium sands and accumulation of fine gravel is significant with a coefficient of determination, $\mathrm{R}^{2}$ of 0.58 and a correlation coefficient, $r$ of 0.76 .

Figure $4 \mathrm{c}$ shows that an increase in the accumulation of fine gravels was strongly influenced by the distribution of the median particle-sizes $\left(D_{50}\right)$ along the riverbeds. This relationship was significant with the coefficient of determination, $\mathrm{R}^{2}$ of 0.73 , and a correlation coefficient, $\mathrm{r}$ of 0.85 . The distribution of the median size $\left(D_{50}\right)$ sand ranges between 0.2 to about $1.4 \mathrm{~mm}$ which imply presence of medium to coarse sands. The distribution of the particle-sizes represented at $\mathrm{D}_{90}$ also a shows a strong influence in the accumulation of fine gravels along the riverbeds. This relationship was significant with a coefficient of determination, $\mathrm{R}^{2}$ of 0.66 and a correlation coefficient, $\mathrm{r}$ of 0.81 . The distribution of particle sizes at $\mathrm{D}_{90}$ varies from 0.1 to $5 \mathrm{~mm}$ in diameter. These imply that the accumulation of fine gravel is associated with a wide range of particle sizes from fine sand to very coarse sands.

Figure 4 showed that accumulation of fine gravel varied between $0 \%$ and $40 \%$ of the total volume of sediments that accumulated on the riverbeds in Kitui South seasonal rivers. The median size particle seems to have more influence in the variation of the amount of fine gravels that accumulate on the riverbed. For example along river Ngulungu in Mutomo, this relationship was observed at Kwa Musingila site where the fine gravel was $9 \%$ while the median sand particle-size $\left(D_{50}\right)$ was $0.45 \mathrm{~mm}$ and at Kwa Joseph Mulatya, the accumulation of fine gravel was $1.8 \%$ while the median sand particle-size was $0.38 \mathrm{~mm}$. Along Memboo river at Kwa Nyamai, the fine gravel accumulation was at $0.8 \%$ while the median sand particle-size was $0.47 \mathrm{~mm}$ and at Kwa Nguute the median size sand was $0.28 \mathrm{~mm}$ when fine gravel accumulation was $0.3 \%$. Another example that showed significant relationship between the median sand particle-size and the accumulation of fine gravel was at Kwa Mwendwa along Muvuko seasonal river in Kanziko ward. Fine gravel accumulation at this site was at $11.6 \%$ while the median particle-size was $0.69 \mathrm{~mm}$. At Kwa Mula along the same seasonal river, the accumulation of fine gravel was $2 \%$ while the median sand particle-size $\left(D_{50}\right)$ was $0.32 \mathrm{~mm}$. The trend showed that as the accumulation of fine gravel increased, the median particle-size also increased.

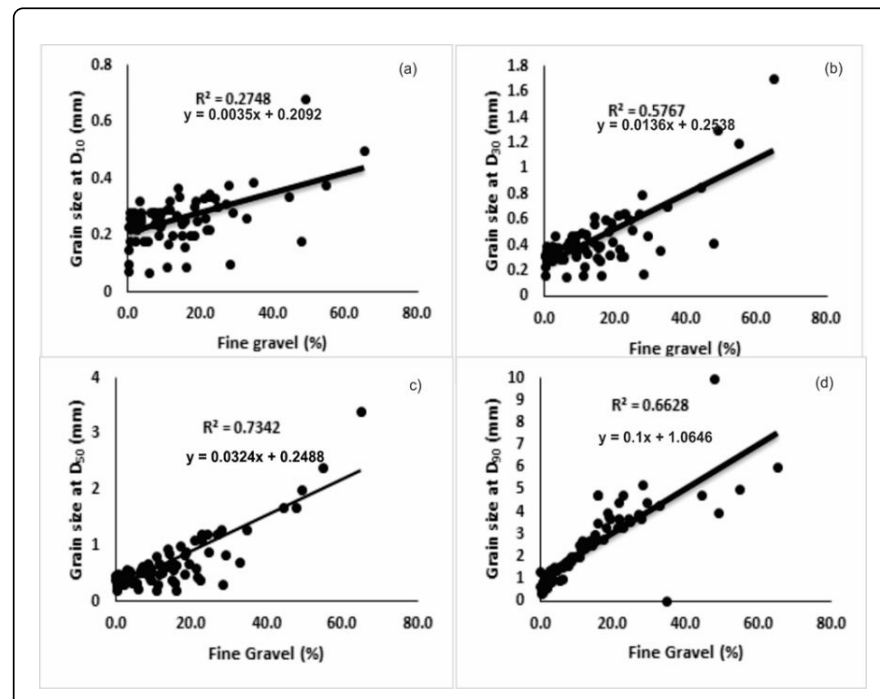

Figure 4: The relationship between the rate of fine gravels accumulation and the distribution of $\mathrm{D}_{10}, \mathrm{D}_{30}, \mathrm{D}_{50}$, and $\mathrm{D}_{90}$ sand particle-sizes in the riverbeds in Kitui South.

In order to determine the relationships established in Figure 4, a regression analysis was done to establish the contribution of different grades of sand in the accumulation of fine gravels. Table 1 shows that the distribution of medium to coarse sands $\left(D_{30} D_{60}\right.$ and $\left.D_{90}\right)$ have a significance influence in the accumulation of fine gravels which is evident with a coefficient of determination, $\mathrm{R}^{2}$ of 0.911 , and a correlation coefficient, $\mathrm{r}$ of 0.95 . This relationship is statistically significant since the F-value is less than 0.05 and the P-Values for $\mathrm{D}_{30}$ $\mathrm{D}_{60}$ and $\mathrm{D}_{90}$ is $0.04,0.00$ and 0.00 , respectively (Table 1 ). 


\begin{tabular}{|c|c|c|c|c|c|}
\hline ANOVA & Df & ss & MS & $\mathbf{F}$ & Significance $F$ \\
\hline & 5 & 12736.60 & 2547.32 & 151.04 & $2.3 \mathrm{E}-37$ \\
\hline & 74 & 1248.02 & 16.87 & & \\
\hline & 79 & 13984.62 & & & \\
\hline \multicolumn{6}{|l|}{$\mathrm{R}^{2}=0.911$} \\
\hline & Coefficients & Standard Error & t Stat & P-value & Lower 95\% \\
\hline Intercept & -7.58 & 1.83 & -4.14 & 0.00 & -11.23 \\
\hline Median (D50) (mm) & -15.36 & 10.16 & -1.51 & 0.13 & -35.62 \\
\hline $\mathrm{D} 10(\mathrm{~mm})$ & -6.77 & 11.25 & -0.60 & 0.55 & -29.18 \\
\hline $\mathrm{D} 30(\mathrm{~mm})$ & 25.77 & 12.24 & 2.10 & 0.04 & 1.38 \\
\hline $\mathrm{D} 60$ (mm) & 15.19 & 5.18 & 2.93 & 0.00 & 4.87 \\
\hline $\mathrm{D} 90$ (mm) & 3.58 & 0.47 & 7.64 & 0.00 & 2.65 \\
\hline
\end{tabular}

Table 1: Sand characteristics that influence the occurrence of gravelly sands.

The results also shows that there is no significant influence of the distribution of the medium sands $(0.2-0.4 \mathrm{~mm})$ represented by the particle size $\mathrm{D}_{10}$ in the accumulation of fine gravels along the riverbeds (Figure 4). In conclusion the accumulation of fine gravels is well associated with the distribution of sand particles ranging between 0.4 $\mathrm{mm}$ and $4 \mathrm{~mm}$ (coarse sands). The median sand particles do not seem to have any relationship with the changes observed in the accumulation of fine gravels as the P-value is 0.13 (Table 1).

Figure 5 a shows that sand particles ranging between 0.1 and $0.3 \mathrm{~mm}$ (fine to medium sands), denoted by $\mathrm{D}_{10}$, have a moderately influence in the accumulation of coarse sand along the riverbeds. This is reflected with a coefficient of determination, $\mathrm{R}^{2}$ of 0.296 and a correlation coefficient, $\mathrm{r}$ of 0.54 (Figure $5 \mathrm{a}$ ). Results also showed that sand particles ranging between 0.1 and $0.5 \mathrm{~mm}$ also had a moderate influence in the accumulation of coarse sand along the riverbeds. This is evident with a coefficient of determination, $\mathrm{R}^{2}$ of 0.269 , and a correlation coefficient, $\mathrm{r}$ of 0.52 in the particle of sand denoted with $\mathrm{D}_{30}$ (Figure $5 \mathrm{~b}$ ).

The accumulation of coarse sand was fairly influenced by the occurrence of median particles of sand. Figure $5 \mathrm{c}$ shows that upto $40 \%$ accumulation of coarse sand is partly influenced by the occurrence of median sand $\left(D_{50} \mathrm{~mm}\right)$ with a coefficient of determination, $\mathrm{R}^{2}$ of 0.23 and a correlation coefficient, $r$ of 0.48 . However the occurrence of sand particles ranging between 0.2 and $4 \mathrm{~mm}$ shows no significant influence in the accumulation of coarse sands (Figure $5 \mathrm{~d}$ ). The coefficient of determination, $\mathrm{R}^{2}$ of 0.08 and correlation coefficient, $\mathrm{r}$ of 0.27 were generally low indicating weak relationship.

The analysis of variance in Table 2 shows similar observations where the particle diameter at $D_{10}$ indicates a significant influence in the variation of accumulation of coarse sands with a significance F-value less than 0.05 and a P-value of 0.04 . The other particles represented as

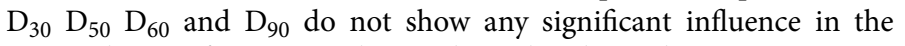
accumulation of coarse sands as indicated with P-value $0.73,0.91,0.70$ and 0.13 , respectively (Table 2 ). The $34 \%$ of the variation in the accumulation of coarse sands is explained by the changes in the distribution of $D_{10}$ particle sizes along the riverbeds. This shows that the medium sands $(0.2-0.4 \mathrm{~mm})$ have a great influence in the accumulation of coarse sands on the riverbeds (Figure 5a). The occurrence of the median sand particle-size did not show any significant relationship with the accumulation of coarse sands in seasonal rivers found in Kitui South.

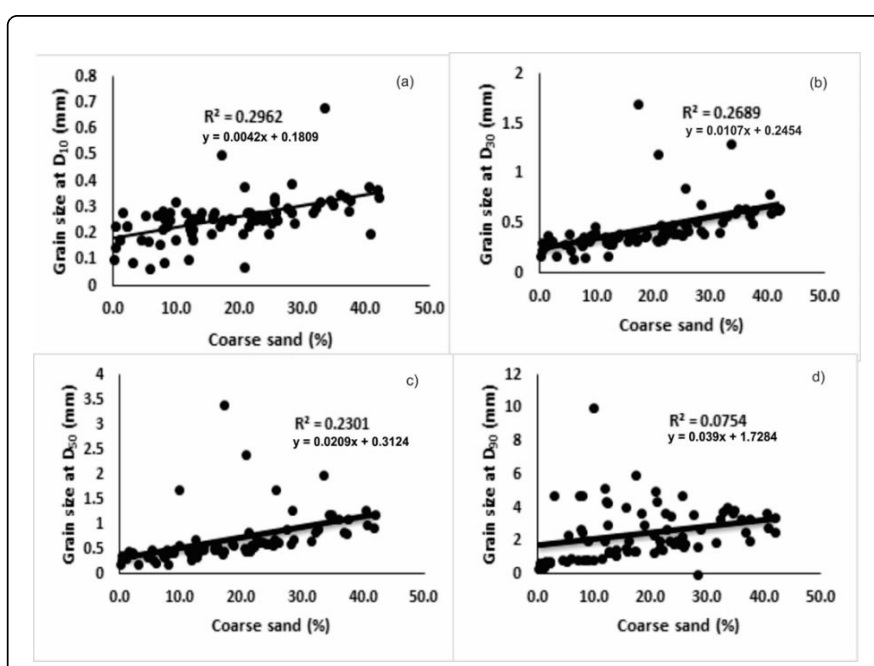

Figure 5: The relationship between the rate of accumulation of coarse sands and occurrence of other particle-sizes.

The results also showed that the accumulation of medium sands increased as the overall sand particle sizes decreased (Figure 6). There is no significant relation between an increase in the accumulation of medium sand and the overall decrease in size of the sand particles occurring on the riverbed. This relationship had a low coefficient of determination, $\mathrm{R}^{2}$ of 0.02 and a correlation coefficient, $\mathrm{r}$ of 0.15 (Figure 6a). A weak relationship was observed between the increase in the amount of medium sands and the decrease in the distributed mediansize sands denoted as $\left(D_{50}\right)$ with coefficient of determination, $R^{2}$ of 0.3087 and correlation coefficient, $r$ of -0.56 (Figure $6 b$ ). The median 
size sand particles in this case ranged between 0.2 and $1 \mathrm{~mm}$ which slightly indicate coarse sands.

\begin{tabular}{|l|l|l|l|l|l|}
\hline ANOVA & Df & SS & MS & F & Significance F \\
\hline Regression & 5 & 3506.21 & 701.24 & 7.45 & $1.05 \mathrm{E}-05$ \\
\hline Residual & 74 & 6969.20 & 10475.41 & 94.18 & \\
\hline Total & 79 & & & & \\
\hline $\mathrm{R}^{2}=0.34$ & & Standard Error & t Stat & P-value & Lower 95\% \\
\hline & Coefficients & -2.33 & -0.57 & 0.57 & -11.08 \\
\hline Intercept & -2.45 & 24.02 & 0.11 & 0.91 & -45.15 \\
\hline Median (D50) $(\mathrm{mm})$ & 2.71 & 26.57 & 2.11 & 0.04 & 3.02 \\
\hline D10 $(\mathrm{mm})$ & 55.97 & 28.93 & 0.35 & 0.73 & -47.45 \\
\hline D30 $(\mathrm{mm})$ & 10.20 & 12.24 & -0.39 & 0.70 & -29.18 \\
\hline D60 $(\mathrm{mm})$ & -4.80 & 1.11 & 1.54 & 0.13 & -0.50 \\
\hline D90 $(\mathrm{mm})$ & 1.71 & & & \\
\hline
\end{tabular}

Table 2: Site characteristics that influence the occurrence of coarse sands.

The distribution of particle size represented as $\mathrm{D}_{60}$ showed a moderate relationship with the accumulation of medium sands in Figure $6 c$. This study found that as the volume of medium sand increased the occurrence of sand particles between 0.2 and $1.5 \mathrm{~mm}$ which is also represented as $\mathrm{D}_{60}$ (medium to coarse sands) decreased with a coefficient of determination, $\mathrm{R}^{2}$ of 0.37 and correlation coefficient, $\mathrm{r}$ of -0.61 . A decrease in the size of coarse sand particles ( 0.5 to $4 \mathrm{~mm}$ ) which was represented as $D_{90}$ (Figure $6 \mathrm{~d}$ ) significantly contributed to the increase in the accumulation of medium sands on the riverbed with a coefficient of determination, $\mathrm{R}^{2}$ of 0.48 and correlation coefficient, $r$ of -0.69 .
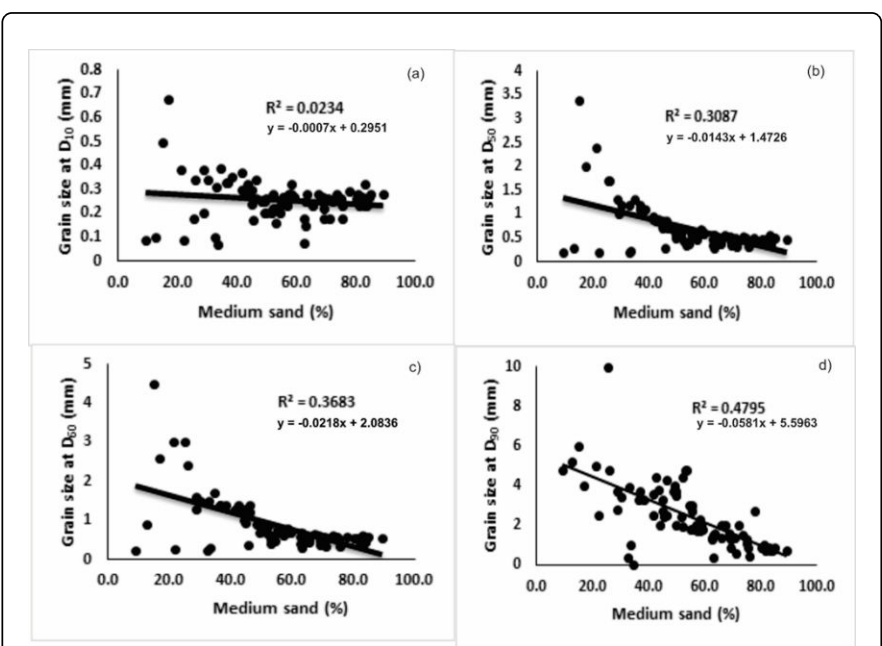

Figure 6: The relationship between the accumulation of medium sands and occurrence of other particle-sizes.

In conclusion the results show that a decrease in coarse sand particle sizes $(0.6-4 \mathrm{~mm})$ results to an increase in the accumulation of medium sands (Figures 6b-6d). Similar observations were made on the correlation analysis where variation in the accumulation of medium sands was strongly attributed to the changes in the distribution of sand particles above the average sizes $\left(D_{90} \mathrm{~mm}\right)$. A significant variation was attributed to the changes in the coarse sands $\left(\mathrm{D}_{90}\right)$ as the P-value was 0.001. Although $\mathrm{D}_{10}$ and $\mathrm{D}_{30}$ particle-sizes (less than $0.5 \mathrm{~mm}$ ) showed a weak relationship, the results showed that to some extent, the distribution of these particles also contributed in the overall accumulation of medium sands as the P-values was in the range of 0.00 and 0.01 respectively.

Eightysix percent of sand accumulated along the seasonal rivers in Kitui South showed $0 \%$ to $20 \%$ composed of fine sand (Figure 7 ). Results showed that the occurrence of fine sands was strongly related to the decrease in the corresponding finer grades of sand $\left(D_{10}\right)$. This relationship existed with a coefficient of determination, $\mathrm{R}^{2}$ of 0.51 and a correlation coefficient, $\mathrm{r}$ of 0.71 . The accumulation of fine sands was moderately influenced by the decrease in particles less than $0.5 \mathrm{~mm}$ (Figures $7 \mathrm{a}$ and $7 \mathrm{~b}$ ). It was concluded that the accumulation of fine sand was probably attributed to the decrease in the sand particle-size ranging between 0.2 and $0.4 \mathrm{~mm}$ (medium sands). This implies that more accumulation of fine sands would occur where the accumulation of medium sediments is minimal.

Figure $7 \mathrm{c}$ showed a weak relationship between the decreases in the median size particles $\left(D_{50}\right)$ and the increase in fine sand accumulation with a coefficient of determination, $\mathrm{R}^{2}$ of 0.19 and correlation coefficient of 0.43 . There was no significant relationship established between accumulation of fine sands and the decrease in size of coarse sands (Figure $7 \mathrm{~d}$ ). The influence of the low grade particle-sizes in the accumulation of fine sands is evident from the results shown in Figure 7 where the particles represented as $\mathrm{D}_{10}$ and $\mathrm{D}_{30}$ showed a significant contribution (56\%) in the observed variation. The significance of these low grade particle sizes was reflected with P-value of 0.001 and 0.04 for $\mathrm{D}_{10}$ and $\mathrm{D}_{30}$, respectively. This implies that the accumulation of fine 
Page 7 of 10

sands is well associated with the accumulation of low grade particlesizes as compared to the coarse sands.

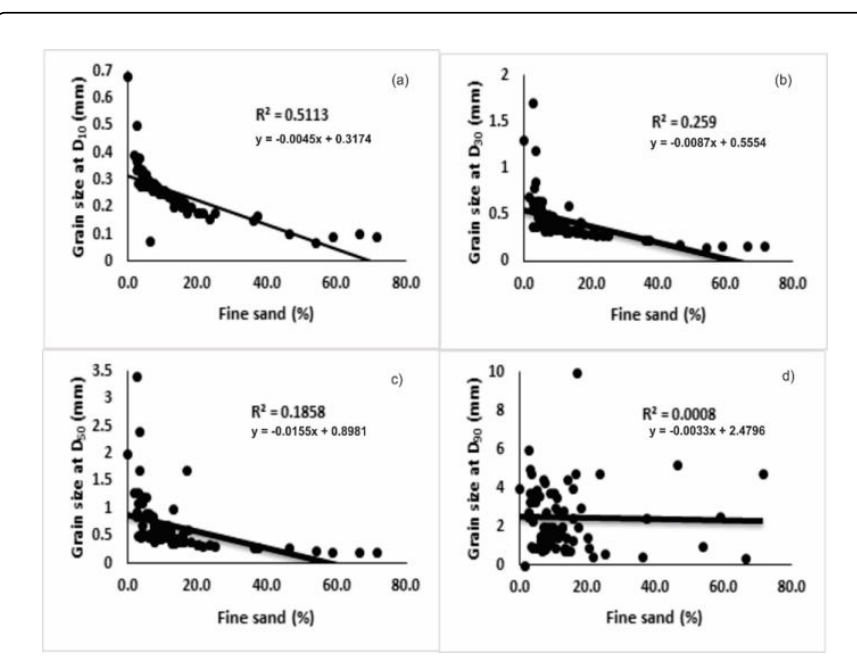

Figure 7: The relationship between the accumulation of fine sands and the occurrence of other particle-sizes.

\section{Relations between sand gradation and stream elevation}

Sites located upstream from the potential sand dam sites were dominated with larger particle-sizes as compared to the sites located downstream where sediments due to the impact of erosion. Figure 8a shows that the overall changes in the sand particles-size ranging between 0.2 to $0.8 \mathrm{~mm}\left(\mathrm{D}_{30}\right)$ was significantly influence by the changes in the elevation along the seasonal streams in Kitui South.

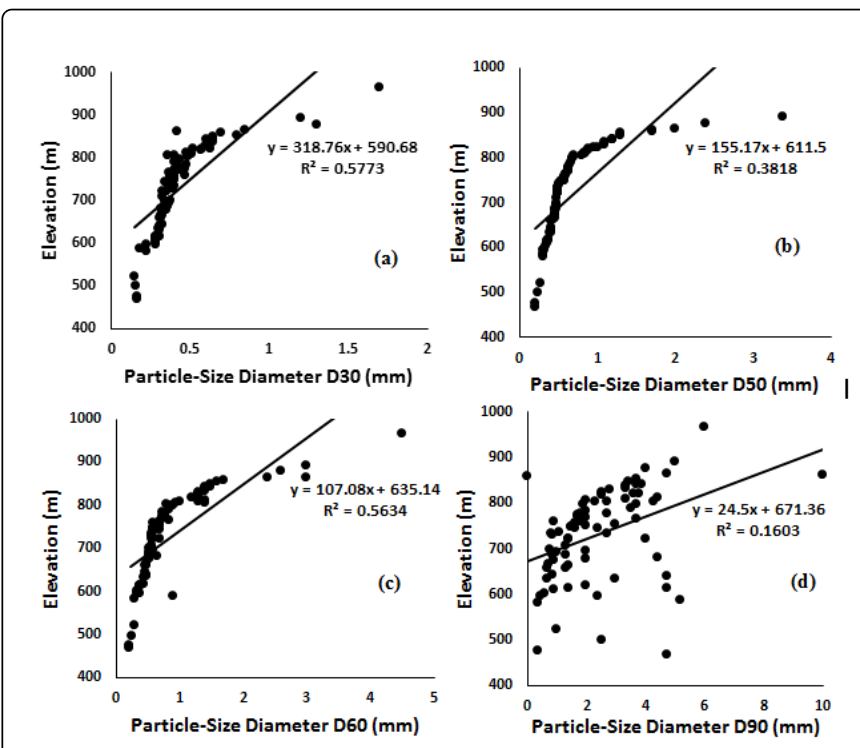

Figure 8: The relationship between elevation and sand gradation along the seasonal rivers in Kitui South.

Sand particle-sizes increased from $0.2 \mathrm{~mm}$ at an elevation of $600 \mathrm{~m}$ to $0.8 \mathrm{~mm}$ at an elevation of $860 \mathrm{~m}$. This shows a strong relationship between elevation and sand gradation especially for the medium and coarse sands $(0.2-0.8 \mathrm{~mm}$ ) (Figure $8 \mathrm{a}$ ) with a coefficient of determination, $\mathrm{R}^{2}$ of 0.58 and correlation coefficient, $\mathrm{r}$ of 0.76 at $\mathrm{D}_{30}$ particle size distribution Figure $8 \mathrm{~b}$ showed similar trend where the median size $\left(\mathrm{D}_{50}\right)$ also increased from about $0.2 \mathrm{~mm}$ to $1.5 \mathrm{~mm}$ at an elevation between $470 \mathrm{~m}$ and $850 \mathrm{~m}$. The influence of elevation was significant in this case with a coefficient of determination, $\mathrm{R}^{2}$ of 0.38 and a correlation coefficient, $r$ of 0.61 .

Figure 8 showed that sand particles which were slightly larger than the average size (i.e., medium to coarse sand $(0.2-2 \mathrm{~mm})$ ) showed a decreased particle diameter along the seasonal rivers in Kitui South (Figures $8 \mathrm{a}$ and $8 \mathrm{c}$ ). A similar trend was observed on coarse sands $(0.2-2 \mathrm{~mm})$ represented as $\mathrm{D}_{60}$, where $\mathrm{R}^{2}$ is 0.56 and $\mathrm{r}$ is 0.75 between an elevation of $450 \mathrm{~m}$ and $900 \mathrm{~m}$. Sand particles sizes larger than $2 \mathrm{~mm}$ (gravels) represented as $\mathrm{D}_{90}$ did not show any significant influence by the changes in the elevation along the seasonal streams in Kitui South $\left(\mathrm{R}^{2}=0.1603, \mathrm{r}=0.40\right)$ (Figure 8d).

\section{The influence of riverbank depth and stream width}

According to Sasol and Acacia (n.d.), very wide streams (more than $25 \mathrm{~m}$ ) are not recommended for sand dams. Reinforcing very wide riverbed is not cost effective. The minimum and the maximum stream widths observed in the study area were $8 \mathrm{~m}$ and $48 \mathrm{~m}$, respectively (Figure 9).

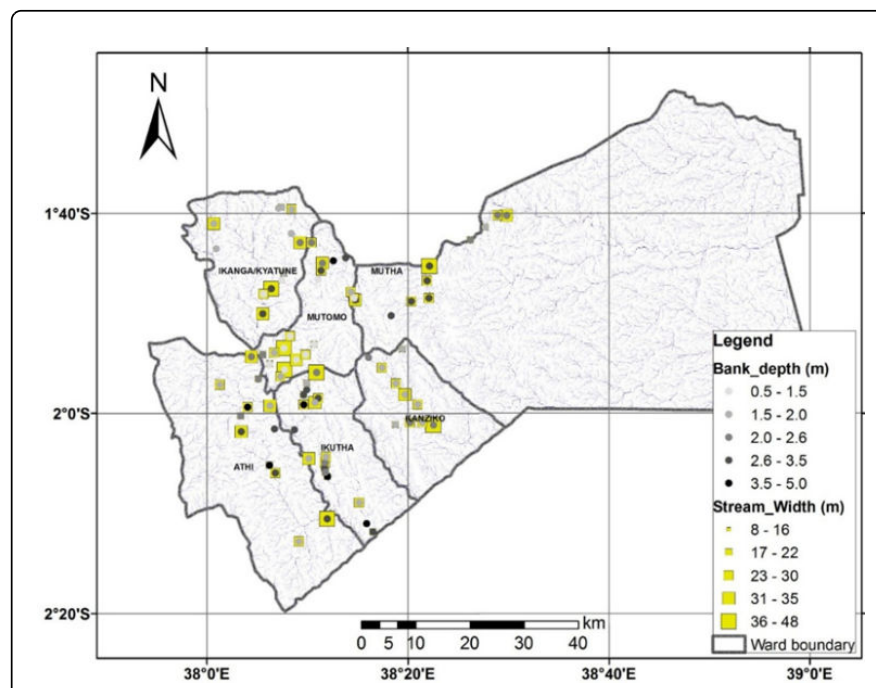

Figure 9: Variation of the stream width and bank depths along the seasonal rivers in Kitui South at the potential sand dam sites (Source Author, 2017).

$55 \%$ of the streams were less than $25 \mathrm{~m}$ wide while $45 \%$ had a width ranging from $28 \mathrm{~m}$ to $48 \mathrm{~m}$ (Figure 9). Suitable sites on the seasonal rivers with stream width less than $25 \mathrm{~m}$ were observed on the hilly areas in Kitui South. Some of the site were observed in Ikanga Ward for example at Kwa Mbithi, Kiangwa along Manzee river, and and Kwa Ngombai along Nzeeu river. Other sites were distributed in the hilly areas of Mutomo and Ikutha wards. There were few sites on the eastern hilly areas of Athi ward for example at Kwa matheka along Nguni river and MukueNdiliu and northern parts of Kanziko Ward. Mutha Ward were least dominated with sites having streams width of less than $25 \mathrm{~m}$.

Kitui South is well distributed with deep riverbank streams. About $80 \%$ of the seasonal streams have riverbank depth ranging between 2 to $5 \mathrm{~m}$. Suitable sites were observed with deep riverbanks for example 
in Mutha ward at Kwa Katu Kilonzo where the riverbank depth was upto $2.6 \mathrm{~m}$, Kwa Mwendwa Kilatya in Kanziko ward the riverbank depth was $2 \mathrm{~m}$ and Nzeveni in Ikutha the riverbank depth was $3 \mathrm{~m}$. Deep riverbanks ranging between 4 to $5 \mathrm{~m}$ were common in the seasonal streams in Athi and Ikutha wards namely Makue Ndiliu and Kwa Meshack Mutua in Athi and Kwa Kiluu, Kwa Kisangau and Kwa Kinene in Ikutha ward.

\section{Suitable sites for sand dams in Kitui south}

Suitable sites were concentrated at the north eastern parts of Ikanga ward (especially along Thua-Syotwii river, Manzee-Ngunga, Nzeeu and Koma-kwa Mbithi (Figure 10).

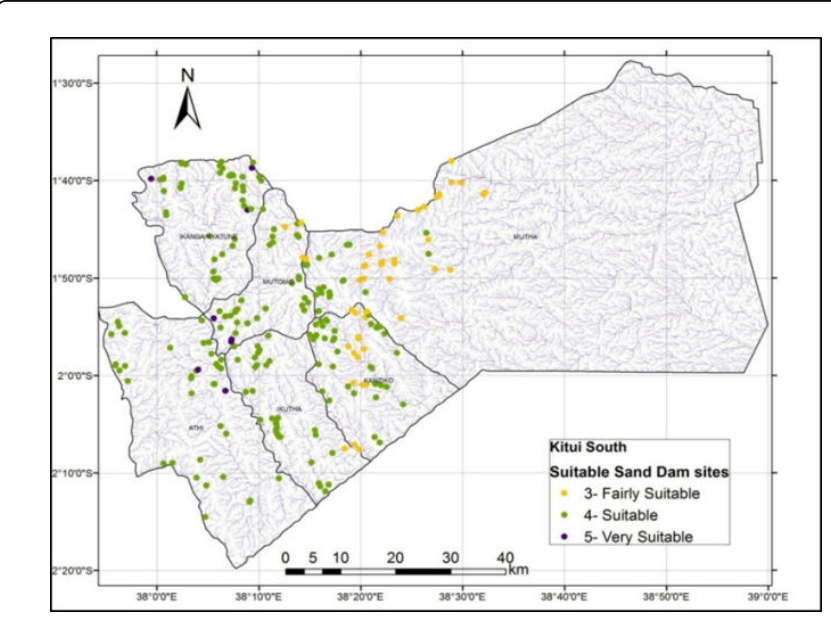

Figure 10: Sand dam suitability map for Kitui South (Source: Author, 2017).

The southern parts of Mutomo ward was also dominated with suitable sites for sand dam construction especially along Ngulungu and Memboo seasonal rivers. There were few sites on the western parts of Mutha ward that were found suitable for sand dam construction especially along Katuluvi-Kanzilu and Kavuti seasonal rivers. In Kanziko ward, suitable sites for sand dam were also well distributedespecially at the northern parts for example along IkunguteMuvuko, Ikutanzale-Muvuko and Muliluni seasonal rivers at the southern parts of the ward. Ikutha ward was found with suitable sites along Mwila-Tiva, Masoma-Tiva, and Ke Mwaa-Muliluni seasonal rivers. Suitable sites for sand dams in Athi Ward were established along Mitanda-Nguni seasonal river which is found near the border to Ikutha Ward and Ndiliu-Ngunyumu seasonal river at the south eastern parts of Athi Ward.

\section{Discussion}

According to Maddrell and Neal [22], high sediment load in the seasonal rivers promotes and dams fill with sand and mature more quickly where seasonal rivers have the greatest sediment load. Sand gradation along the seasonal rivers in Kitui South is spatially varied. Majority of the streams in Kitui South are dominated by medium sand $(66 \%)$ and coarse sands $(21 \%)$. The uniformity coefficient $(\mathrm{Cu})$ and coefficient of gradation $(\mathrm{Ck})$ were applied in the classification of sands based on their particle size distribution. $26.3 \%$ of the sites were found to be 'well-graded coarse sands' distributed in Athi 3, 3 in Ikutha, 2 in Kanziko, 3 in Mutomo, 6 in Mutha and 4 in Ikanga Ward, 6.3\% were 'well-graded fine sand' distributed in small quantities along the streams on the hilly areas of Athi and Ikutha wards. $48.8 \%$ of the sites were dominated by 'well graded medium sands' which were equally distributed in Ikanga, Mutomo, Ikutha and Kanziko wards and few sites in Athi and Mutha. The study also found that $59 \%$ of the potential sand dam sitesare dominated with uniform sands while $30 \%$ are intermediate. The sites accumulated by the uniform sands were categorized as suitable for sand dam's construction in Kitui South. These sites were 6 sites in Athi at Kwa Mutunga, Kwa Matheka, Kwa Nyamai, Mukue, Kwa Kasuku, and Kwa Sila Mutiso, 12 sites in Ikutha ward along KeMwaa, Nzeveni and Masoma-Tiva seasonal rivers, 5 sites in Kanziko ward one on Ikutanzale seasonal river and the rest along Ikungute-Muvuko river, 5 in Mutha along Katuluvi-Musila-Kanzilu seasonal river, 12 in Mutomo ward distributed in three streams name Memboo, Ngulungu and Katiliku-Masaa seasonal river, and 8 sites were found in Ikanga Ward along Koma-Kwa Mbithi, Manzee-Katitika, and Nzeeu seasonal streams.

Other parameters which were found significant in the determination of sand gradation along the seasonal streams included the particle sizes represented as $D_{10}, D_{30}, D_{60}$ and $D_{90}$ (expressed in millimeter). The advantage of using these parameters is that they give a more representative statistic derived from the sieve analysis results as also observed in Petersen N [10]. These parameter were found significant in the determination of the distribution of sand particle sizes along the riverbeds unlike when only the median grain size as a parameter is applied $[10,19]$. Kitui South is widely spread with uniform medium and coarse sands distributed in Athi, Ikanga, Mutomo, Kanziko, and Ikutha wards Mutha wards. Well-graded sands are observed in Ikutha and Athi wards.

\section{Dominant particle-sizes}

Limited studies have been undertaken to explain if there is any spatial relationships that exist on the characteristics of the potential sand dam sites. However, several studies confirm that the occurrence of coarse and uniform medium sands is critical for high performance of sand dams $[22,23]$. It is therefore important to make sure that any sites selected for sand dam construction has a considerable accumulation of the appropriate sands for a sustainable good performing of sand dam. The higher the percentage of uniform coarse sands, the greater the storage capacity of that dam [10,24]. Coarse sands are deemed the best for sand dams [25]. Unlike the fine gravels which give an average drainable porosity of $25 \%$, uniform and unconsolidated coarse sand gives an average drainable porosity of $27 \%$ for the accumulation and storage of subsurface water [26]. Most of the investigated sites in Kitui South dominated with coarse and medium sands. The accumulation of medium sands also corresponded with the accumulation of coarse sands which concur with other findings [21]. Areas with limited accumulation of coarse sands were observed with significant accumulation of medium sand which is also considered suitable for sand dam [22]. Accumulation of medium sands in the seasonal rivers in Kitui South is relatively higher than the other grades of sand occurring along the riverbeds. The results show that accumulation of medium sand ranged between $20 \%$ and $80 \%$. This represents $62 \%$ of the sites which were observed to have accumulated medium sand. Although the median sizes $\left(D_{50}\right)$ was found important in a previous study [21] in the determination of sand particle-size distribution on the sand dam sites, in this study, $\left(D_{50}\right)$ as well as $D_{60}$ did not show any significant influence in the accumulation of medium sands along the riverbed ( $\mathrm{P}$-value $=0.17$ and 0.27 respectively). However, the occurrence of fine sands showed a strong relationship 
with the decrease in the medium size particles of sand ranging between 0.2 and $0.4 \mathrm{~mm}$.

\section{Riverbed gradient and sand accumulation rate}

The river bed gradient determines the rate at which sands accumulate at a given site [22]. Grounds located on gentle slope (0-10 degrees) along the riverbed are recommended for sand dam because they provide maximum potential for water storage. Previous studies show that steep gradient accelerates the movement of riverbed sediments down the stream due to high influence of gravity and high energy of the river [27,28]. The results show that $86 \%$ of the investigated sites in Kitui South were suitable for the sand dam with a river bed gradient ranging from $0 \%$ to $8 \%$ which fall within the recommended range for the slope of a potential suitable site for sand dam [22]. High riverbed gradient will decrease water infiltration. High volumes of fine grained sands were observed at the lowlands far from the erosional plains.

\section{Influence of elevation on the sand accumulation rate}

The accumulation of sands along the riverbed is influenced by several factors along the river which include both physical and human related factors [6]. This study confirmed that there is no significant relationship between the change in elevation and the rate at which sand accumulate on the riverbeds. Substantial accumulation of sand accumulates up to an average of $50 \%$ medium sand at an elevation between 600 and $900 \mathrm{~m}$ above sea level. This study concluded that sand accumulation along the seasonal rivers depended more on the stream gradient than the elevation of a site located along the stream. The favourable stream gradient was between 0.5 and $4 \%$. This imply that even if the elevation is high, other attributes such as favourable slope would encourage sand accumulation at the site located in such site and therefore considered suitable for sand dam.

\section{The influence of elevation on sand gradation}

Sand gradation along stream channels is associated with changes in the river morphology [22]. More erosion occurs upstream while the deposition occurs at the floodplains where the river energy and erosional activities are minimal. Vertical soil erosion occurs at the upstream when the river energy is still high while lateral erosion occurs at the depositional plains due reduced energy of the river under the influence of low terrain [25]. The findings show that changes in the elevation has a strong influence on the dominant sand particles-sizes found on the riverbed. This is attributed to the distance travelled by the sediments down the stream whereby smaller particles imply that they have been transported over a longer distance to the point of deposition than the coarse sediments which occur at the higher elevation near the river head [12].

\section{Uniformity of sands and suitability for sand dam}

The coefficient of uniformity was applied to show how uniformity of the sands varied across the study area. High accumulations of coarse uniform sediments increase the storage capacity and the abstraction potential from a sand dam [22]. In order to maximize the extractable water from a sand dams it is important to construct sand dams at the sites with uniform-sands $[10,22,25]$. Results show that Uniformity Coefficient $(\mathrm{Cu})$ varied between 16.67 and 1.74 with a mean of 3.42 . The coefficient of gradation $(\mathrm{Ck})$ varied between 2.55 and 0.33 and a mean of 0.94 . Most of the sites located along the seasonal streams in
Kitui South (86\%) were accumulated by uniform medium sands $(\mathrm{Cu}<3)$. The rest of the sites $(14 \%)$ were dominated with coarse and gravelly sands. This means that $86 \%$ of the investigated sites in Kitui South are suitable for sand dams. Other studies found that medium sand is also applicable in sand dams [10]. This study established that uniform medium sand have higher storage capacity than well graded sands.

Excellent sites were concentrated in places where the supply of coarse sands was sufficient. This is the case observed especially on the western parts of the study area where the basement rocks are dominant unlike in the regions covered with sedimentary rocks in the east. The riverbanks in this region are firm and rocky hence good for anchoring the sand dam wall. This is contrary to the eastern region (flood plains) especially in the larger parts of Mutha where the geology does not favor siting of sand dams. Most parts in the western region of the study area are also characterized with occurrence of relatively coarse sand which is recommended for excellent sand dams. The lowlands in Mutha is covered with relatively finer particles which originate from the erosional plains in the west and are deposited after long distance hence the reduction in grain size. The eastern region of the study area shows unfavorable and unsuitable sites for sand dam due to weak riverbanks, minimal exposure of bedrock where the sand dam wall can be constructed and common occurrence of shallow riverbanks. Very suitable sites were observed in sparsely different distributed areas Makutano Kivili, Kwa Ngombai in Ikanga Ward, Kwa Beth Mutinda in Ikutha Ward, Kwa Kasilu in Mutomo and Itumba B in Mutha. However this ward can be supplemented with underground water. Shallow wells can also be dug in this area since there is possible enough recharge.

\section{Conclusions}

Suitability of sites for sand dams varies throughout the study area. The analysis on particle-size distribution played major role in determining the relationships between the suitability of sites and sands gradation for seasonal rivers found in Kitui South. Sands available along the riverbed in most of the seasonal rivers in Kitui South were well-graded. $86 \%$ of the sites considered suitable for sand dam are dominated with uniform medium size sands which imply that majority of the sites capable of having high capacity for water storage. The rate at which sands accumulate on the riverbed did not show any relationship with several factors namely; the riverbed gradient, sand particle-size, and elevation. On the other hand the difference in the dominant grade size of sand varied significantly with changes in the elevation.

Coarse sands occurred at high elevation riverbeds while fine sands accumulated in the depositional areas with low gradient. However, majority of the suitable sites for sand dams are in Kitui South were found in the transitional zones where the medium sand were dominant. 59\% of the investigated sites in Kitui South were found to have uniform sands, $30 \%$ had intermediate and only $11 \%$ had wellgraded sands. Out of the 47 sites, $59 \%$ had uniform sands; $86 \%$ were dominated with uniform medium size sands and hence are suitable for sand dam. Only $10 \%$ of the sites were dominated with fine sands while the rest, $4 \%$ of the visited sites were dominated with coarse and gravelly sands. These findings imply that $59 \%$ of the sites located along the seasonal rivers in Kitui South are highly potential and are suitable for sand dams. The distribution of different grades of sands along the riverbed showed a significant association with the distribution of different grades of sands. Suitable sites were concentrated on the western parts of Kitui South where the basement rocks are dominant 
Citation: Mutati K, Kitheka JU, Otieno E (2018) Sand Gradation in Seasonal Rivers and their Suitability for Construction of Sand Dams in Kitui South, Kenya. Hydrol Current Res 9: 295. doi:10.4172/2157-7587.1000295

Page 10 of 10

unlike in the western parts of the area where the dominant bedrock are sedimentary. The suitable sites identified in Kanziko, Ikutha, Mutomo Ikanga, and some parts in Athi are located on firm and none fractured bedrock hence good for anchoring the sand dam wall. This is contrary to the eastern region (flood plains) especially in the larger parts of Mutha where the geology does not favor siting of sand dams. Most parts in the western region of the study area are characterized with medium and coarse sands which are favorable for excellent sand dams.

\section{References}

1. Puttemans S (2004) Potential for small scale irrigation from groundwater dams in South Kitui, Kenya, Katholieke Universiteit Leuven Faculty of Agricultural and Applied Biological Sciences.

2. Aerts J, Lasage R, Beets W, De Moel H, Mutiso G, et al. (2006) Robustness of sand storage dams under climate change. Vadose Zone Journal 6: 572-580.

3. Boko M, Niang I, Nyong A, Vogel C, Githeko A, et al. (2007) Africa. Contribution of Working Group II to the Fourth Assessment Report of the Intergovernmental Panel on Climate Change. Cambridge University Press pp. 433-467.

4. Nelson KD (1985) Design and Construction of Small Earth Dams. Melbourne, Inkata Press.

5. Nepal S, Wolfgang-Albert F, Arun Shrestha B (2014) Upstreamdownstream linkages of hydrological processes in the Himalayan region. Ecological Processes.

6. Gijsbertsen C (2007) A study to upscaling of the principle and sediment transport processes behind sand storage dams. Kitui District, Kenya. Vrije Universiteit, Amsterdam.

7. Maddrell S (2016) Securing water supply with sand dams. Article available at: www.excellentdevelopment.com

8. Hoogmoed M (2007) Analyses of impacts of a sand storage dam on groundwater flow and storage. VU University, Amsterdam.

9. Nissen-Petersen E (2007) Water Supply by Rural Builders. For Danish International Development Assistance (DANIDA). ASAL Consultants Ltd, Nairobi, Kenya.

10. Van Haveren BP (2004) Dependable water supplies from valley alluvium in arid regions. Environmental Monitoring and Assessment 99: 259-266.

11. Alderlisten M (1990) Mean Particle Diameters. Part 1: Evaluation of Definitions Systems 7: 233-241.

12. Hut R, Ertsen MW, Joeman N, Vergeer N, Winsemius H, et al. (2008) Effects of sand storage dams on ground water levels with examples from Kenya. Physics and Chemistry from the Earth 33: 56-66.
13. Love D, Singh A (2011) A water balance modelling approach to optimizing the use of water resources in ephemeral sand rivers. River Research and Applications 27: 908-925.

14. Bouwer $H$ (2000) Integrated water management: emerging issues and challenges. Agricultural Water Management 45: 217-228.

15. Maddrell S (2010) The miracle of sand dams. Appropriate Technology 2: 26-27.

16. Walling DE, Fang D (2003) Recent trends in the suspended sediment loads of the world's rivers. Global and Planetary Change 39: 111-126.

17. Retsch GH (2009) Sieve Analysis in Quality Control. Available at: www.retsch.com.

18. ISO (2001) Representation of results of particle size analysis-Part 2: Calculation of average particle sizes/diameters and moments from particle size distributions. Available at: hsevi.ir/RI_Standard/File/7455.

19. Barkhordari J (2015) The pre-selection of suitable sites for small underground dams in arid areas using GIS. A case study in Yazd. Ardakan Watershe 6: 18-27.

20. Maddrell S, Neal I (2012) Sand dams: a Practical Guide. Excellent Development, London.

21. Munyao JN, Munyoki JM, Kitema MI, Kithuku DN, Munguti JM, et al. (2004) Kitui sand dams: Construction and operation. SASOL foundation.

22. Rempel H, Nyaga CW, Manzi HK, Graff P (2005) Water in the sand: an evaluation of SASOL's Kitui Sand Dams Project. SASOL Foundation, Mennonite Central Committee and Canadian Food Grains Bank.

23. Borst L, de Haas SA (2006) Hydrology of Sand Storage Dams-A case study in the Kiindu catchment, Kitui District, Kenya. Free University of Amsterdam, The Netherlands.

24. Jankowski P (1995) Integrating geographical information systems and multiple criteria decisionmaking methods. International Journal of Geographical Information Science 9: 251273.

25. Beimers PB, Eick van AJ, Lam KS, Roos B (2001) Improved design sandstorage dams, Kitui District, Kenya. Project Report, Delft University of Technology.

26. Beimers PB, Eick van AJ, Lam KS, Roos B (2001) Building sand-storage dams, SASOL Foundation Kitui District, Kenya. Practical work report, Delft University of Technology.

27. Afifi S, Fuladipanah M (2015) Subsurface Dam Site Selection Using GIS (Case Study: Chamsiab Plan, Masjedsoleyman, Iran). Indian Journal of Fundamental and Applied Life Sciences pp: 2231-6345.

28. Burger AS, Malda W, Winsemius HC (2003) Research to Sand-storage dams in Kitui district. Delft University of Technology. 